\title{
DIURNAL AND ANNUAL MEAN WEATHER CYCLES OVER NSUKKA, NIGERIA DURING 2010/2011
}

\author{
C. O. Onyenucheya ${ }^{1}$ and H. C. Nnamchi ${ }^{2}{ }^{*}$ \\ 1, 2 DePartment OF GEOGRAPHY, UNIVERSITY OF Nigeria, NSUKKA. ENUGU STATE. NIGERIA \\ E-mail addresses: ${ }^{1}$ onyenaucheyaobinna@yahoo.com, ${ }^{2}$ hyacinth.nnamchi@unn.edu.ng
}

\begin{abstract}
This study analyzed the mean diurnal and annual cycles of weather elements over Nsukka using the data for 2010 and 2011. It is found that diurnally the peak/trough values occur as follows: temperature (15/06 hrs), relative humidity (06/15 hrs), atmospheric pressure (10/17 hrs), and wind speed (16/19 hrs). The occurrence of the maximum in temperature prior that of wind speed suggests that the dominant winds over Nsukka may be thermally driven. The mean annual peaks/troughs are viz; temperature (March/August), wind speed (December/October), relative humidity (August/January), rainfall (September/December and January) and atmospheric pressure (Uuly/April). A roughly curvilinear fit is found between the annual rainfall and relative humidity: while rainfall appears insensitive to humidity changes during the drier months, its response tends to be linear during the rainy season.
\end{abstract}

Keywords: Diurnal Cycle, Annual Cycle, Curve Fitting, Weather Modulations, Nsukka Weather

\section{INTRODUCTION}

The concept of cycles points to the periodic reoccurrence of a weather phenomenon; the mean weather events tend to repeat themselves with some order. In this context, cycles entail patterns and order in the mean state-since the departures from the mean are not taken into account. Geophysical analogues of weather cycles include solar cycle (the earth revolves round the sun approximately every 365 days), hydrological cycle (rain falls to the earth surface and goes back to the atmosphere through evaporation and transpiration), rock cycle (the transformation of rock from one rock type to another). Weather cycles may be categorized into two viz: simple cycles and complex cycles. The mean climatic seasonal cycle of the year viz: winter, spring, summer, autumn and then back to winter in the temperate latitudes, and rainy and dry season in the tropics represent a simple cycle.

The underlying notion in the search for an orderly behaviour in the weather is that much of the activities humans engage in-like what to eat or wear is affected by the rhythms of the weather daily. The cyclic behaviour of the weather affects us in all its variety. Most of the time the effects are familiar, nonetheless the weather never repeats in exactly the same fashion. This underscores the need to search weather records for the occurrence of cycles. Within the meteorological community the debate continues as to whether patterns exist and if they do, whether they are sufficiently well established to provide the physical basis for weather forecasting.

An increasing number of studies have been devoted to the cycles of meteorological variables over large areas [1-6]. Most of these studies focus on the examination of mean values of meteorological variables in order to show weekly cycles or weekly effects. The analyses were designed to find differences between the weekend and the working week, using the Saturday through Monday and Wednesday through Friday periods to define both periods respectively [7]. This is anchored on the fact that human activities (e.g. commercial transportation, industrial activity, etc.) are commonly reduced during weekends compared to weekdays - especially in the western industrialized countries.

Over the Atlantic coast of the United States and neighboring oceanic areas, weekly cycles has been observed in the rainfall and tropical cyclones activity and linked to the downwind pollution transport from the urbanized eastern seaboard [8]. In eastern China, winter diurnal temperature range (DTR) anomalies tend to be larger for weekends compared to weekdays and are associated with increased maximum temperature and total irradiance but decreased relative 
humidity [9]. On the other hand, the summertime DTR anomalies display a much stronger negative weekend effect (i.e. smaller DTR in weekends) linked to decreased maximum temperature and decreased total solar irradiance but increased relative humidity and a greater number of rainy days. The weekly difference is suggested to be physically related to the direct and indirect effects of anthropogenic aerosols [9].

The present study examines the cyclic behavior of the weather over Nsukka, Nigeria. Nsukka is the second most populated urban centre in Enugu State-after the Enugu Capital Territory. The rapidly increasing urban population of Nsukka necessitates an improved understanding of the basic features of the weather. Thus, we examine the diurnal (during the course of the day) and annual (during the course of the year) weather cycles over Nsukka.

\section{MATERIALS AND METHODS}

\subsection{The Study Area}

Nsukka is one of the 17 local government areas of Enugu State, Nigeria (Figure 1). Nsukka lies between latitudes $06^{\circ} 43^{\prime} 30^{\prime \prime}$ and $07^{\circ} 00^{\prime} 30^{\prime \prime} \mathrm{N}$ and longitudes $07^{\circ} 13^{\prime} 00^{\prime \prime}$ and $07^{\circ} 35^{\prime} 30^{\prime \prime} \mathrm{E}$ and has a land area of $40,750 \mathrm{~km}^{2}$ with a mean elevation of $551.68 \mathrm{~m}$. The climate of Nsukka is classified as the tropical wet and dry (that is, Aw) based on the Koppen's classification scheme. The area receives ample sunshine throughout the year. March is the warmest month of the year with temperature averaging $27^{\circ} \mathrm{C}$ while August is the coldest month with an average temperature of $22.9^{\circ} \mathrm{C}$ [10]. This is in agreement with the findings of the present study, although actual values vary slightly since the data are for different periods.

\subsection{Data Collection}

Data for this research work were measured at the Meteorological Observatory of the Department of Geography, University of Nigeria, Nsukka Campus. The Observatory provides high resolution (every 30 minutes) measurements of weather elements based on automatic recording. In this study, readings of temperature $\left({ }^{\circ} \mathrm{C}\right)$, rainfall $(\mathrm{mm})$, pressure $(\mathrm{hPa})$, relative humidity (\%), and wind speed $\left(\mathrm{ms}^{-1}\right)$ for $2 y \mathrm{ys}$ (2010 and 2011) were analyzed.

\subsection{Data Analysis}

Data on continuous weather elements (temperature, humidity, pressure, and wind speed) were analyzed on hourly and monthly basis. On the other hand, rainfall occurrence is considered discrete in time and so the monthly accumulated amounts were analyzed. For the continuous elements, the 30 minutes recordings were first averaged on an hourly basis. Then, the hourly means were analyzed from 01 to 24 hours Local Standard Time (LST). As this work is concerned with the mean state, the two-year mean of each element is calculated.

The relationship between the annual cycles of pairs of weather elements was examined. Here, a three-stage curve fitting procedure was adopted. First, we employed a linear fit (first order model). Then realizing that some elements when paired exhibited a curvilinear relationship; we modeled them using second and third order polynomial functions.

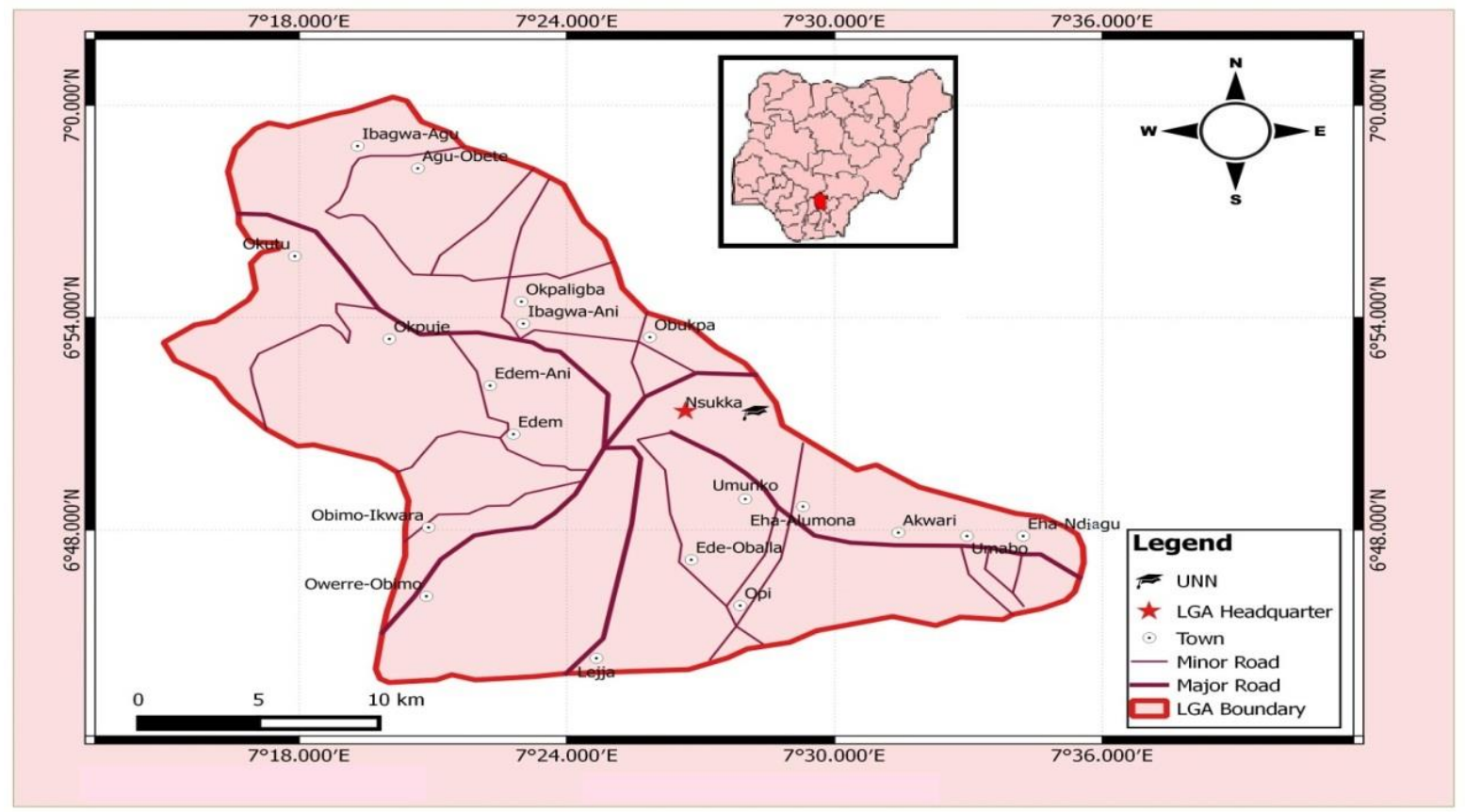

Figure 1: The location of Nsukka in Nigeria 
Given a weather element ( $\mathrm{Y}$ ) which is taken to be a response element that evolves with another (X) taken to be the predictor element, the first order model of their linear relationship is given by the function:

$$
Y=a_{0}+a_{1} X+\varepsilon
$$

Where $a_{0}$ and $a_{1}$ are the intercept and slope of the curve, respectively and $\varepsilon$ is an error term. Equation (1) is a simple linear function, representing the relationship between two weather elements $\mathrm{X}$ and $\mathrm{Y}$. However, if the time evolution of $\mathrm{X}$ and $\mathrm{Y}$ is not linear, it becomes necessary to describe their relationship using other curve fitting methods. Here, we find that the appropriate model will require polynomial terms and may be generalized as follows:

$$
Y=a_{0}+a_{1} X+a_{2} X^{2}+\ldots+a_{n} X^{n}+\varepsilon
$$

Where $\mathrm{n}$ represents the order of the polynomial terms. As shown in section 4, the relationship between pairs of weather elements over Nsukka appear to be best described by polynomials in the range of $1 \geq n \leq 3$; where $\mathrm{n}=1$ corresponds to a linear function of the form shown as equation (1).

\section{RESULTS AND DISCUSSIONS}

\subsection{Diurnal Cycles}

In this section, we first describe the diurnal cycle of air temperature, wind speed, atmospheric pressure and humidity (Figure 2).Nsukka is characterized by low temperatures during the early hours of the day (Figure 2a). This rises gradually in the morning hours, reaches a peak in the afternoon and then falls as dusk approaches. The diurnal minimum temperature $\left(22.43^{\circ} \mathrm{C}\right)$ occurs by $06 \mathrm{hr}$ LST and the maximum $\left(29.47^{\circ} \mathrm{C}\right)$ by $15 \mathrm{hr}$. At noon (12hrs LST) the sun reaches the local zenith and as such its rays and
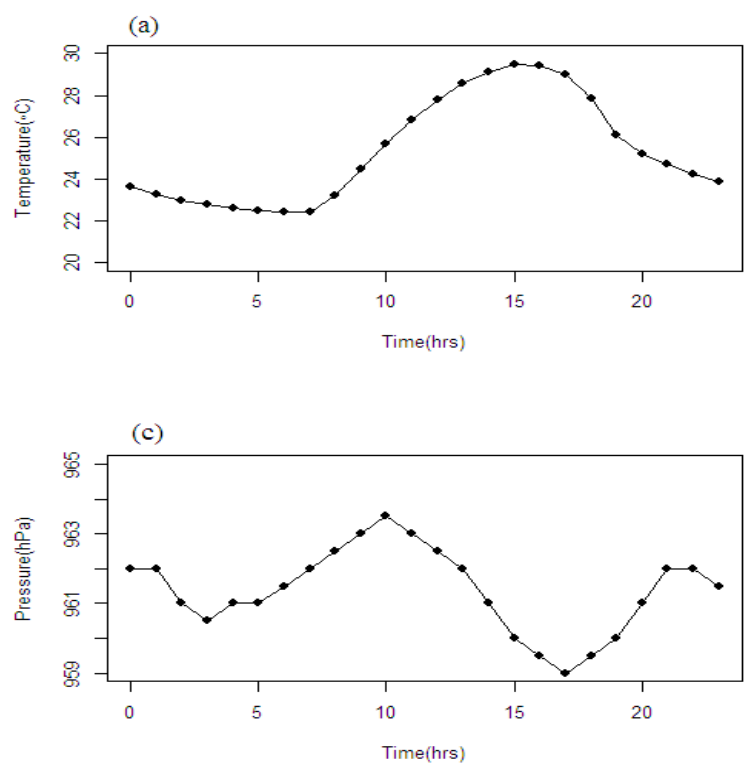

consequently the shortwave radiation reaches the surface with the greatest intensity. However, the earth's atmosphere is not heated directly by shortwave solar radiation but by the long wave terrestrial radiation emitted from the surface. This explains the time lag between when the sun reaches the local zenith and maximum diurnal temperature.

Wind speed is maximum by $16 \mathrm{hr}$ LST with speed of $2.63 \mathrm{~ms}^{-1}$ and the minimum is by $19 \mathrm{hr}$ LST with a speed of $0.64 \mathrm{~ms}^{-1}$ (Figure $2 \mathrm{~b}$ ). Winds over the area on average fall under the calm, light air and light breeze of the Beaufort wind scale (Singleton, 2008). One possibility is that averaging the wind speed data over the entire year masks out important seasonal differences, exemplified by the peaks in wind speed in December and March (see discussions in section 3.2). Nonetheless, the analysis here reveals important time lag in which the air temperature leads wind speed by $1 \mathrm{hr}$. This suggests that on a mean annual basis, diurnal wind fluctuations in Nsukka may be thermally driven. That is, surface heating creates localized convective cells which may induce the wind circulation thereby redistributing atmospheric mass and creating localized pressure differences. Figure 2c shows the diurnal cycle of atmospheric pressure in Nsukka during the study period. The maximum atmospheric pressure (963.5 $\mathrm{hPa}$ ) occurs by $10 \mathrm{hr}$ LST and the minimum (959.0 $\mathrm{hPa}$ ) occurs by $17 \mathrm{hr}$.

The highest amount of relative humidity (84.32\%) occurs around $06 \mathrm{hr}$ LST (the time when temperature is lowest) and the lowest amount of $54.5 \%$ occurs by $15 \mathrm{hr}$ LST when temperature is at its maximum (Figure 2d).
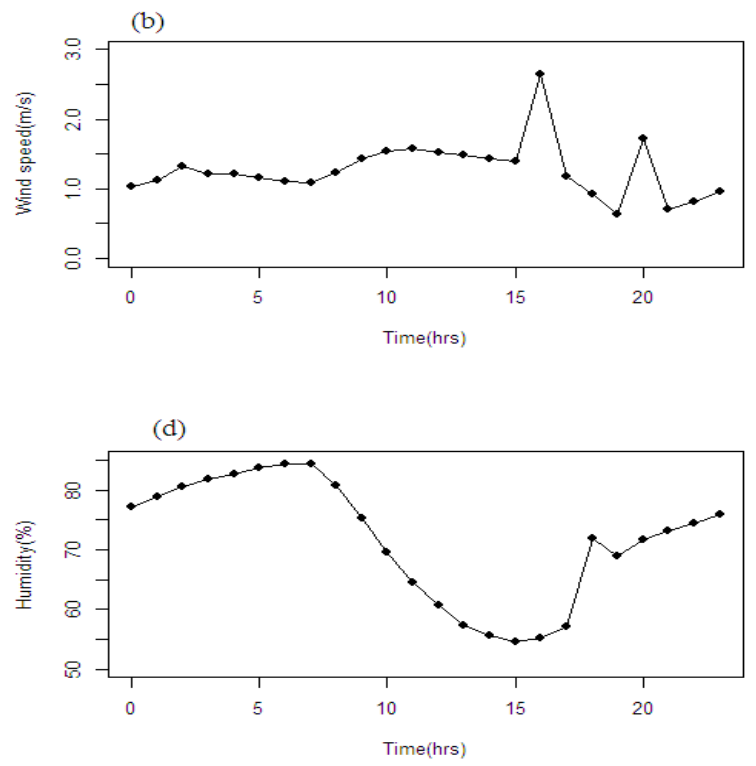

Figure 2: Values of weather elements as a function of the hours of the day. 
This inverse relationship may be linked to the interaction between air temperature and saturation vapour pressure. If the air temperature increases, the saturation vapour pressure also increases thereby raising the water vapour holding capacity and in the absence of a corresponding change in the air actual water vapour content lowers the relative humidity. On the other hand, when air temperature decreases, so does the saturation vapour pressure and as the saturation vapour pressure approaches the actual vapour pressure, the relative humidity increases.

\subsection{Annual Cycles}

The annual cycle of air temperature shows that the month with maximum temperature over Nsukka is March, having temperature of $27.87{ }^{\circ} \mathrm{C}$. On the other hand, the minimum occurs in August with temperature of $23.29^{\circ} \mathrm{C}$ (Figure 3a). Maximum wind speed occurs in December with speed of $1.79 \mathrm{~ms}^{-1}$ and the minimum of $0.89 \mathrm{~ms}^{-1}$ in October (Figure $3 \mathrm{~b}$ ). The December peak may be indicative of the harmattan winds while the secondary peak in April may denote the onset of the monsoon winds over Nsukka as $48.7 \mathrm{~mm}$ of rainfall is observed in this month. On the other hand, October may be seen as a transition between the withdrawal of the monsoon and the onset of the harmattan which may explain the relative calmness.

Annually, maximum atmospheric pressure over the area occurs in the month of July with pressure of 963.4
$\mathrm{hPa}$ while the minimum (959.9 $\mathrm{hPa}$ ) occurs in April (Figure 3c). Relative humidity is lowest in January (45.53\%) and is highest in the rainy month of August having a value of $85.01 \%$ (Figure $3 \mathrm{~d}$ ). The rainfall cycle shows that over the area, there is minimal or absence of rainfall at the beginning and end of the year. The peak of rainfall occurs in September with $108.55 \mathrm{~mm}$ and the least being in January and December for which no rainfall was observed (Figure 3e).

\section{RELATIONSHIP IN ANNUAL CYCLES OF THE WEATHER ELEMENTS}

Having shown the annual cycles of the weather elements in the previous section, in what follows we describe the relationship between some of the elements using the two-year monthly mean data. The three stage curve fitting approach described in section 2 is applied here.

From Figure $4 \mathrm{a}$, it can be seen that at periods of no rainfall (that is, rainfall $=0 \mathrm{~mm}$ ), relative humidity is at the threshold of $\sim 45 \%$. A look at the annual cycle plot (Figure 3d) suggests that this is mainly during the dry season. Thus, although the atmospheric water vapour content may fluctuate, it hardly reaches saturation. However, as the rainfall amount increases (during the rainy season), there is an increasing tendency towards a curvilinear relationship.
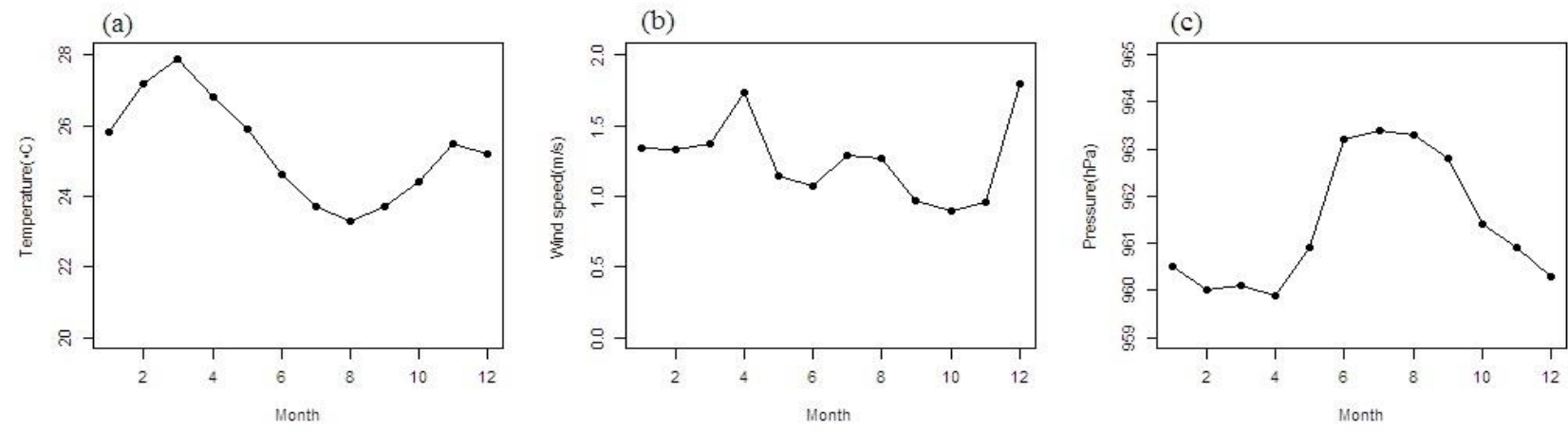

(d)
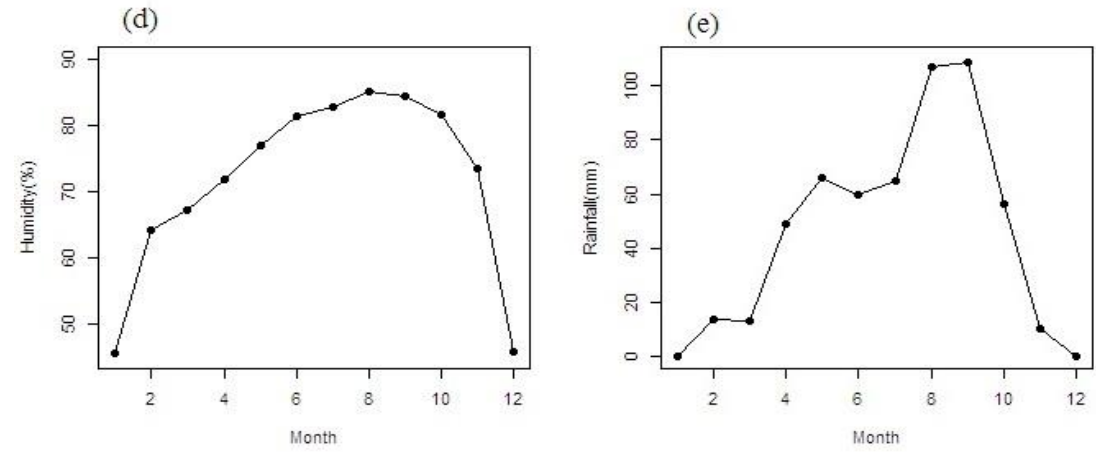

Figure 3: Values of weather elements as a function of the months of the year 
The relationship between air temperature and atmospheric pressure is shown in Figure $4 \mathrm{~b}$. The pressure, volume and temperature are related by the equation of state under a wide range of laboratory conditions. Generally, the atmospheric gases also obey the ideal gas equation:

$$
p V=m R T
$$

Where $p, V, m$ and $T$ are the pressure (Pa), volume $\left(\mathrm{m}^{3}\right)$, mass $(\mathrm{kg})$ and absolute temperature (in Kelvin, $\mathrm{K}$, where $\mathrm{K}={ }^{\circ} \mathrm{C}+273.15$ ) and $R$ is the gas constant for $1 \mathrm{~kg}$ of a gas. But $m / V=\rho$, where $\rho$ is the density of the gas. And so the gas equation may be re-written as follows:

$$
p=\rho R T
$$

Since $\rho$ and $R$ are constants, one would expect a positive linear relationship between $p$ and $T$. As shown in Figure $4 \mathrm{~b}$ however, this expectation is not met for Nsukka using the monthly mean data: $p$ and $T$ have a somewhat inverse relationship. One explanation is that averaging the data for the entire month may have masked the sensitivity of $p$ and $T$. Thus, further studies are needed to better understand how the horizontal pressure and temperature gradients are related to the redistribution of atmospheric mass and the associated time scale.

\section{SUMMARY AND CONCLUSION}

This study examined the diurnal and annual cycles of meteorological elements-temperature, rainfall,

(a)

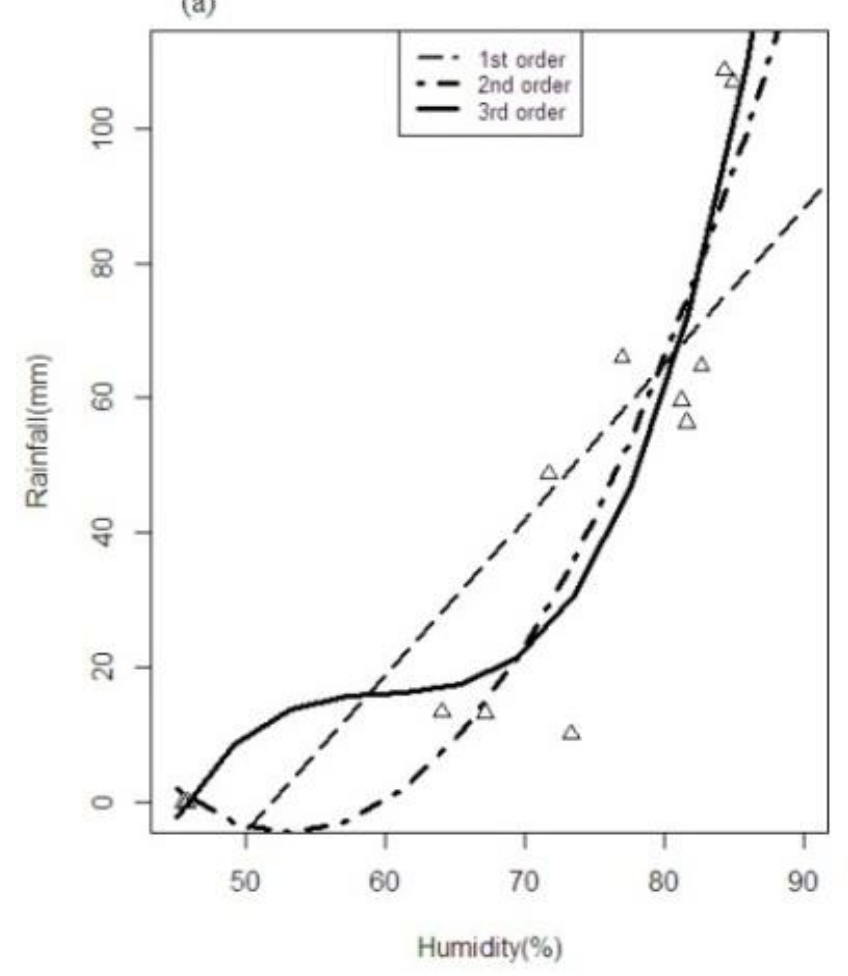

humidity, pressure, and wind speed over Nsukka. Analyses reveal that diurnally, air temperature peaks by $15 \mathrm{hr}$ LST with a minimum at $06 \mathrm{hr}$, relative humidity is highest by $06 \mathrm{hr}$ and is lowest by $15 \mathrm{hr}$, atmospheric pressure is highest by $10 \mathrm{hr}$ and lowest at $17 \mathrm{hr}$, wind speed peaks at $16 \mathrm{hr}$ and is lowest by $19 \mathrm{hr}$. On annual cycle, we found air temperature to be highest in March and lowest in August; wind speed peaks in December and minimum occurs in October, August has the highest amount of relative humidity and the least being in the month of January. Rainfall peaks in September while the minimum is experienced in January and December, maximum atmospheric pressure occurs in July and the minimum in April. The study further described a curvilinear relationship between relative humidity and rainfall using monthly data.

It is important to note that our analysis is based on 2 yrs (2010 and 2011) for which uninterrupted record is available. In essence, long term changes in the cycles due to interannual, decadal or multidecadal modulations in the climate system are not accounted for in this study. Thus, further studies utilizing longer time series are needed to characterize such modulations. Despite this caveat, the results provide key features of the diurnal and annual cycles of weather over Nsukka.

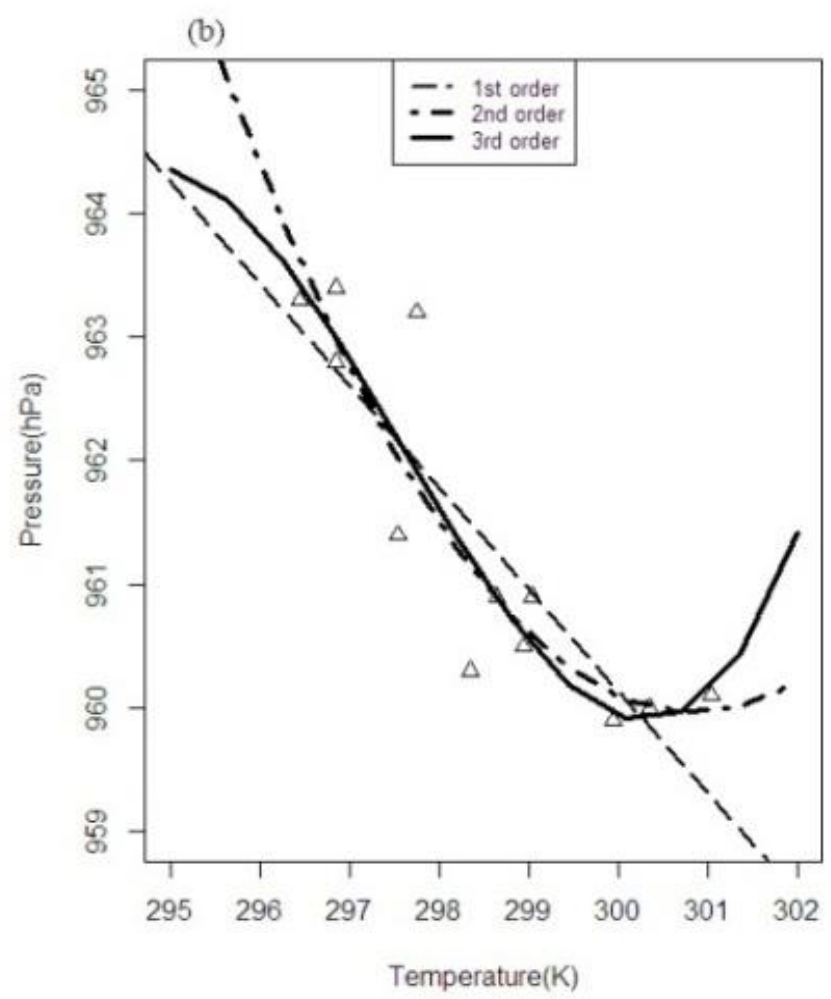

Figure 4: Co-evolution of the monthly weather elements 


\section{REFERENCES}

[1] Gordon, A. H. "Weekdays warmer than weekends?" Nature, Vol.367, pp 325-326. 1994.

[2] Kim, K.-Y, R. J. Park, K.-R. Kim, and H. Na. "Weekend effect: Anthropogenic or natural?" Geophysical. Research Letters, Vol. 37, Issue 9, 2010.

[3] Forster, P. M. and Solomon, S. "Observations of a 'weekend effect' in diurnal temperature range", Proceedings of National Academy of Sciences, USA,pp 11225-11230. 2003.

[4] Bell, T., Yoo, J. M., and Lee, M. I. "Note on the weekly cycle of storm heights over the southeast United States", Journal of Geophysical Research, Vol. 114, Issue D15, 2009.

[5] Choi, Y. S., Ho, C. H., Kim, B. G., and Hur, S. K. "Long-term variation in midweek/weekend cloudiness difference during summer in Korea", Atmospheric Environment, Vol. 42, pp 67266732.2008 .

[6] Mullayarov, V. A., Karimov R. R., Kozlov V. I., and Poddelsky, I. N. "Possible weekly variations in the thunderstorm activity", Journal of Atmospheric and Solar-Terrestrial Physics, Vol. 67, 397-403. 2005.

[7] Sanchez-Lorenzo, A., P. Laux, H, Hendricks Franssen, J. Calbo, S.Vogl, A. K Georgoulias and J. Quaas. "Assessing large-scale weekly cycles in meteorological variables: a review", Journal of Atmospheric Chemistry and Physics, Vol. 12,pp 5755-5771.2012.

[8] Cerveny, R. S. and Balling, R. C. "Weekly cycles of air pollutants, precipitation and tropical cyclones in the coastal NW Atlantic region". Nature, Vol.394, pp 561-563.1998.

[9] Gong, D.-Y., Guo, D., and Ho, C.-H. "Weekend effect in diurnal temperature range in China: Opposite signals between Winter and summer", Journal of Geophysical. Research, Vol.111, Issue 18, 2006.

[10] Phil-Eze, P. O. "The influence of elevation and aspect on plant species diversity in a tropical landscape of Nsukka plateau in Nigeria", Tropical Built Environment Journal, Vol. 1, Number 3, ,pp 255 - 266.2012.

[11] Singleton, F. "The Beaufort scale of winds - its relevance, and its use by sailors", Weather, Vol. 63, Number 2, pp 37-41. 